\title{
Research on the Application of Computer Aided English Teaching
}

\author{
Huahong Rao ${ }^{1}$ \\ ${ }^{1}$ Tongren University, Tongren, Guizhou, 554300 \\ 346591653@163.com
}

KEYWORDS: Computer Aided English; Teaching; Application Study

\begin{abstract}
With the rapid development of education and teaching the theory of improvement and development of science and technology, the combination of the two is also constantly play a role in teaching. From the initial electronic courseware, to teaching software, to customize the learning platform, all reflect a profound impact on education by science and technology. This article will focus on the application of modern technology in teaching English writing a study, based on the platform of the computer teaching aids to make a comparison with computer-assisted learning software, an active role in both theory and practice demonstrate computer in English writing teaching.
\end{abstract}

\section{Introduction}

For a long time, most of the English classroom teaching methods are supplemented by a few basic modes of practice, with the continuous improvement of educational theory, science and technology advances, more and more new technology to be applied to the field of education and teaching them. Multimedia computer as a symbol of computer-aided instruction in recent years increasingly become the mainstream of education. Advent of the computer has greatly facilitated blended learning and ubiquitous development and popular learning. But after the author's preliminary investigation found that the current application of educators to computers and computer-assisted teaching in English teaching is still confined to hearing and reading exam on the subject and objective corresponding project, while the translation and writing exam correspond with subjective topic almost no research projects. On writing courses, the traditional classroom teaching basically follows the same pattern: teachers speak so-called writing methods and writing skills, students are very passive listening; teacher preparation issues, required students to write. Under such writing teaching environment, students' individual thinking is severely restricted, to play a serious impediment to the initiative of the students.

\section{The Traditional Lecture Method of Teaching Evolution}

Typical early education teaching methods most commonly used is the "teaching method", but this period has only limited teaching method "about" and "explain." The basic process can be summarized as "teacher talk - Students listening - reading - remember - Practice." Features taught law teachers in the teaching and interpretation of knowledge, students can only passively accept mechanical knowledge, basically explain the textbooks and teachers' knowledge presented in almost exactly the same, students reflect on the issues are basically the same with the textbooks or teachers 
to explain Students rely on repeated memory machine learning, flexible poor, master and practical application of knowledge is not flexible enough.

Based on the theoretical basis of the theory of apperception, Herbart proposed educational theory and principles, these theories influence on later schooling are far-reaching. For example, Herbert stressed that "past experience students will form groups apperception, new ideas related to the absorption process, these apperception group will play an important role." Schema theory emphasizes, original drawings in the minds of students assimilate new learning task in the process will play an important role.

The first stage: to understand is to understand the new knowledge to enable students to accept new knowledge in teacher explicitly taught at; the second stage: the association is to contact old and new knowledge, is to enable students in the teacher's help, the new knowledge and old knowledge establish a link between; the third stage: The system is built on knowledge systems, is to guide or help students to generalize knowledge and draw conclusions; fourth stage: the method is by means of homework, etc. so that students learn hands-on knowledge, so that knowledge truly solutions to problems. After this, four Herbart pedagogy has been his student Ziller (Tuiskon Ziller, 1817-1882) and Rein (Wilhelm Rein, 1847-1929) to improve and supplement, and gradually developed into five stage approach and the teaching process is divided into five stages.

First stage: preparation can also be referred to as a preparation phase, at this stage teachers need to arouse students' prior knowledge, but also to stimulate student interest in learning new knowledge; the second stage: four teaching method is presented in clear stages Teachers should explicitly teach new knowledge to students; the third stage: Contact is to establish contact between the old and new knowledge, is relatively old and new knowledge and abstract phases; Phase IV: summary stage, teachers should help students to draw conclusions, definitions or rules, forming a new group apperception; Fifth stage: exercises or exercises for students to be able to skillfully use by answering derived concepts or rules, are able to apply the new knowledge acquired and consolidated. The school is fully aware of the intrinsic link between education and psychology, and tried to arrange and adjust teaching from a psychological point of view, so that teaching can be a reasonable step.

Mid-20th century, the rapid development of science and technology, all areas of social life are deeply influenced by technological development, education also faces enormous challenges of the new technological revolution. People began to consider the use of new issues and new technology research and education theory and interdisciplinary teaching. Modern psychology and thinking mechanism of human brain science activities carried out in-depth research, epistemology complete understanding of the process of human summarized, cognitive psychology of the human brain to accept information activities and information activities to select research, system theory, cybernetics and information processing theory emerged. Teaching practice is deeply affected by social and technological change, but also with many new topics and introduces new teaching model start to appear. Therefore, at this stage there have been many new teaching ideas and theories in the field of education, at the same time generate a lot of new teaching mode.

\section{The Emergence and Development of Computer-Aided Instruction}

Computer-assisted instruction refers to computer-assisted teaching or substitute teachers in the operative part of the task, to teach students knowledge and provide skills training teaching methods. Computer aided instruction to provide students with a good learning environment and personalized. And traditional teaching methods are very different, computer-aided teaching hypertext, multimedia, 
artificial intelligence and knowledge base and other computer technologies are organically integrated together, so that more comprehensive teaching and learning process more humane.

Late 1980s and early 1990s, the emergence of the multimedia computer is no doubt becomes a revolution in the computer field. Multimedia computer with powerful integrated word processing, graphics, sound and image capability is wonderful. Teaching, multimedia computer is by virtue of its wealth of expression, showing a remarkable ability irreplaceable, CAI also rapidly developed towards multimedia direction. In 1991, the Massachusetts Institute of Technology research and development of computer networks Athena system that connects distributed in every corner of the school's 50 high-speed laser printers, students and teachers can use the high-speed printer through Athena in school any computer, which the students and teachers of the research produced a great help, Athena computer network system also opens up a new era of networked computer-aided instruction.

As an important symbol of the development of network technology, the computer by the introduction of a widespread concern in the community. IOT cloud, cloud security, cloud storage, cloud gaming, computer applications in various fields is to let people see the great potential and power of computer development. October 2007, Google began to promote the company together with IBM computers include Carnegie Mellon University, Massachusetts Institute of Technology, Stanford University, University of California at Berkeley and the University of Maryland, including several US university campus plan, The program aims to reduce the cost of distributed computing technology in academic research spent, and provide software and hardware equipment and related technical support for computer-related universities. And can the students to large-scale computing-based research network development plans. In November, IBM made Blue Cloud "Blue Cloud plan" to further promote the development of computers in schools. March 2008 Tsinghua University joined the scheme, the computer begins officially entered into the field of education and scientific research. The rise of computer-assisted instruction, which greatly promoted the tele-education and ubiquitous learning flourish.

\section{Modern Distance Education}

Modern distance education is a new educational model with the development of electronic technology and modern information technology generated. With the computer and multimedia technology development and communications technology, especially the rapid, teaching methods Distance education Internet also will make a huge difference. Modern Distance Education in modern communications technology as the main medium to-face, correspondence and self-study as the main form of teaching is the optimal combination of a variety of media education.

Modern Distance Education can effectively play to the characteristics of distance education. Orthodox face to face with respect to education, distance education teachers and separation, is a non-face teaching activities organization. Distance education is a way to cross the school, the educational system and teaching model regional organization teaching. The most important feature of distance education is that students and teachers separated. Compared with the face to face education, distance education the biggest advantage is that breaking the limitations of time and space. In addition to the students' learning time and space is relatively more freedom than, students get relatively more learning opportunities. At the same time distance education can make teaching a certain extent, the scale was expanded; and teaching costs are significantly reduced. $।$

1990s, with the development of information technology and networks, information and network technology based on the third generation of modern distance education classes. July 1994, the Ministry of Education, which is under the auspices of the then State Education Commission, "China 
Education and Research Network (CERNET) Demonstration Project" jointly built by Tsinghua University and other 10 universities. The network's network management is divided into four levels, namely national network center; master node regional network centers and regions; provincial education research networks and campus networks. CERNET is the first based on TCP / IP protocol of a public computer network, a national network of centers located in Tsinghua University, responsible for the operation and management backbone, provincial nodes distributed in the country, located in 38 cities in 36 universities . Currently CERNET has opened 28 international and regional channels, with the United States, Canada, Britain, Germany, Japan and Hong Kong to achieve a network interconnection, the total bandwidth has reached 10G. CERNET networking with education and scientific research units of more than 2,000 networked hosts reached 120 million units, the total number of users has exceeded 20 million people. It can be said, to a great extent based on the modern distance education information and network technology, promoted the pan in the development of learning in modern education had a huge impact.

\section{Conclusion}

Nevertheless, as an assisting device, computer assisted vocabulary teaching can never replace the significance of teachers. There are some unavoidable shortcomings that computer assisted vocabulary teaching posses. As the instructor of teaching activity, teachers should be aware of the conception of letting students be the focus of the teaching process, make full play of their initiatives and combine traditional vocabulary teaching with various teaching mode together.

\section{REFERENCE:}

[1] Ausubel, D.P. Educational Psychology: A Cognitive View [M]. New York: Holt, Rinehart \& Winston, 1978

[2] Bruner, J. The Process of Education [M].Cambridge Harvard University Press, 1960.

[3] Corder, S. P. The Significance of Learner Errors [J]. International Review of Applied Linguistics, 1967.

[4] David, J. Constructivism and Computer-Mediate Communication In Distance Education [J]. The American Journal of Distance Education, 1995. 